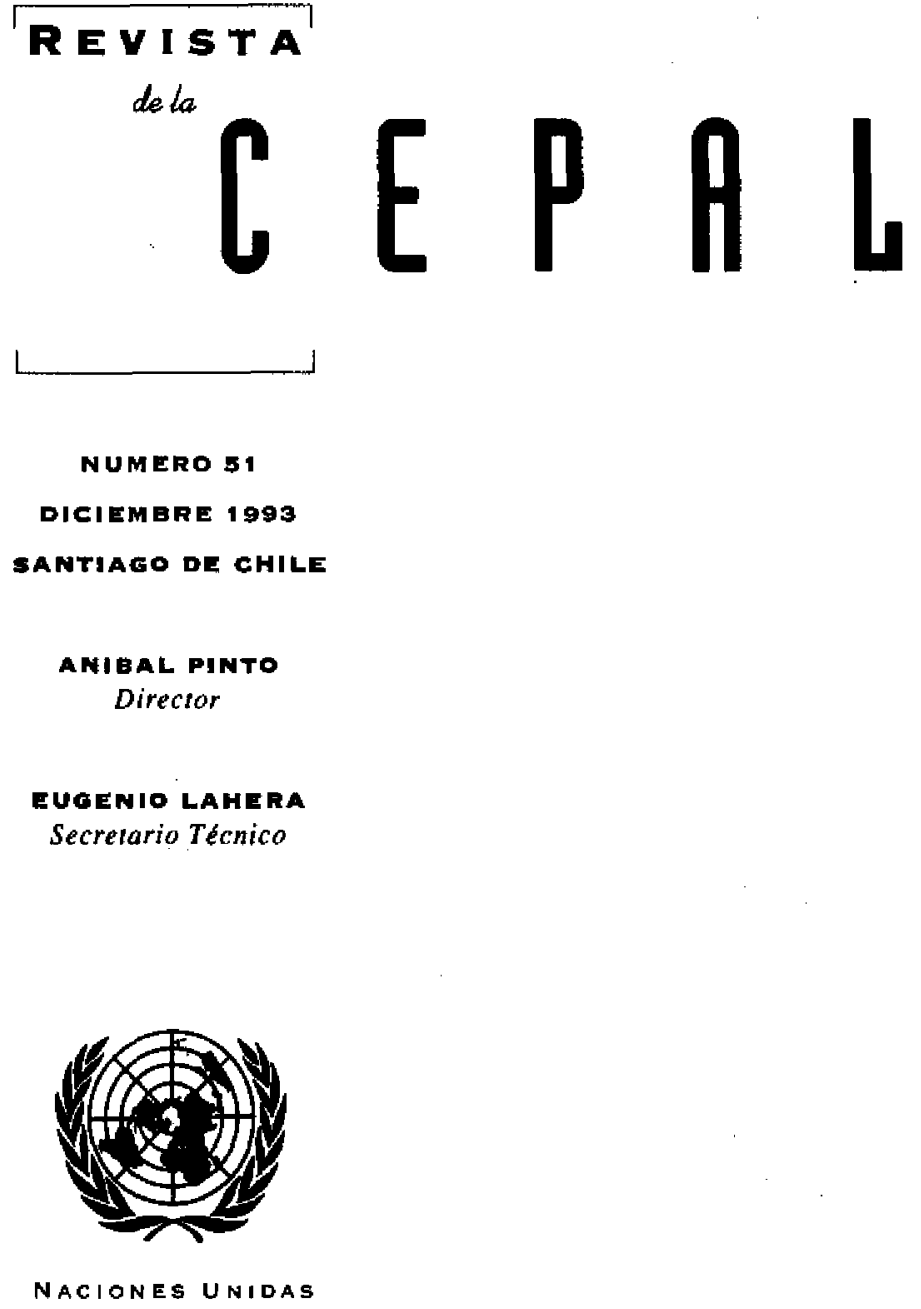


Inauguración de la Sala Fernando Fajnzylber y lanzamiento de la Revista de la CEPAL N² $\mathbf{5 0}$

Gert Rosenthal y Alejandro Foxley

Las transnacionales y la Industria en los paises en desarrollo

Michael Mortimore

¿Dónde estamos en política Industrial?

El desafío de la competitividad Industrial

Rudolf M. Buitelaar y Leonard Mertens

Integración y desintegración social rural

Martine Dirven

Los pueblos Indigenas y la modernidad

John Durston

Productividad y trabajo de la mujer en los Estados Unidos

Inés Bustillo y Nancy S. Barrett

Efectos de las corrientes de capltal sobre la base monetarla

111

Helmut Reisen

Viejas y nuevas políticas comerclales

Daniel Lederman

Integración y desviación de comerclo

Renato Baumann

Integración europea y comerclo latinoamericano

Miguel Izan

El actual debate sobre los recursos naturales

Fernando Sánchez Albavera

Orlentaclones para los colaboradores de la Revista de la CEPAL 


\section{Viejas y nuevas políticas comerciales}

\section{Daniel Lederman}

Funcionario de la CEPAL en Washington.
Las estrategias de desarrollo de América Latina han estado historicamente vinculadas en forma inextricable con la teoría y la política de comercio. El autor sostiene aquí que el viejo argumento de la industria incipiente y el nuevo planteamiento de] comercio estratégico son fundamentalmente similares. Entre sus semejanzas, ambos justifican la proteccion selectiva de ciertos sectores económicos. Entre sus diferencias, el argumento de la industria incipiente justifica la proteccion temporal, en tanto que la proteccion estratégica de ciertas industrias se justifica indefinidamente. Sin embargo, en lo que atañe a transformar economías orientadas hacia el interior en economías orientadas hacia el exterior, la diferencia entre política comercial y política industrial se torna nebulosa. Ello se debe a que con ambos argumentos en favor del proteccionismo, se llega a la conclusión teórica de que en materia de políticas la decisión optima y que más incrementa el bienestar, incluso en el caso de los sectores estratégicos, es el uso de subvenciones. Después de examinar los fundamentos teóricos de ambos argumentos, el ensayo concluye con un conjunto de observaciones y prescripciones respecto de las repercusiones económicas, políticas e institucionales que deben tenerse en cuenta al elaborar un plan de desarrollo estratégico viable y de largo plazo. 


\section{I \\ El debate contemporáneo en torno al proteccionismo y el desarrollo en América Latina}

Los debates sobre las estrategias de desarrollo están impregnados de análisis teóricos de las políticas comerciales. El argumento de la industria incipiente esgrimido en favor del proteccionismo fue fundamental para justificar la estrategia de sustitución de las importaciones, que fue aplicada con vigor por los países de América Latina en el decenio de 1950 y posteriormente. Los que abogaban tanto por un ajuste estructural heterodoxo como por uno ortodoxo en el decenio de 1980 sostenían que era necesaria la promoción de las exportaciones (por la vía de las devaluaciones internas y la liberalización de los mercados destinada a intensificar la competitividad) para aumentar los ingresos de divisas, financiar los pagos del servicio de la deuda externa y equilibrar la balanza interna y externa. Hacia la segunda mitad del decenio dichas políticas habían producido resultados variados. Debido a que las altas tasas reales de interés en el ámbito internacional llegaron a su punto máximo en 1985, a que una prolongada recesión en los países de la OCDE redujo el crecimiento del comercio internacional y a que empeoró la relación de precios del intercambio para los exportadores de productos primarios, el proceso de ajuste al comienzo atenuó la demanda de importaciones, en tanto que los ingresos de exportación permanecieron en un relativo estancamiento (Bianchi, Devlin y Ramos, 1987). A comienzos del decenio de 1990 , los países que han realizado rápidos procesos de reforma, como Argentina y México, han dependido de la afluencia de capitales para financiar los crecientes déficit en cuenta corriente. Chile sigue siendo el único caso en que las exportaciones impulsan el crecimiento económico, mientras que la afluencia de capitales ha contribuido a crear presiones alcistas en su tipo de cambio.

El debate sobre las estrategias de desarrollo y las políticas comerciales en América Latina gira en la actualidad alrededor de la conversión de economías orientadas hacia adentro en otras orientadas hacia afuera. El ex Secretario Ejecutivo de la CEPAL, Norberto González, ha llegado a la conclusión de que el vuelco de las economías hacia el exterior puede entenderse de dos maneras diferentes. Por una parte, se puede traducir en estrategias centradas en la exportación de nuevos bienes y servicios, y en la conquista de nuevos mercados. Por otra, se puede interpretar como el desmantelamiento del proteccionismo, lo que permitiría la libre afluencia de productos extranjeros (González, 1988). La selección de políticas comerciales no se puede limitar sólo a medidas de protección o apertura con el fin de dar origen a un ajuste estructural beneficioso. En una economía en desarrollo, el paso desde una orientación hacia adentro a una hacia afuera, aumentando a la vez la productividad marginal de la mano de obra, no se logra en estos términos simplemente liberando en forma indiscriminada las fuerzas del mercado.

En este contexto, el proteccionismo como medio de promover las exportaciones es esencial para el debate sobre las estrategias de desarrollo. La nueva justificación del proteccionismo basada en el comercio estratégico es una teoría reciente pero tentadora. En el presente ensayo se compara este argumento con el antiguo argumento de la industria incipiente, con el fin de evaluar las semejanzas y diferencias. Al examinar las alternativas en materia de políticas comerciales, la lista de opciones se limitará a los aranceles y subvenciones en general. Por ende, las diferencias entre las "políticas industriales" y las "políticas comerciales" aparecen difusas. No se abordan las llamadas políticas neutrales, como los gastos fiscales en educación y capacitación, ni en investigación y desarrollo tecnológico. Este planteamiento se justifica por el hecho de que tanto el argumento de la industria incipiente como el del comercio estratégico presuponen que algunos sectores son superiores a otros desde el punto de vista de los beneficios que pueden obtenerse de su protección.

La noción de la ventaja comparativa, que se centra en las diferencias nacionales como fuerzas impusoras del comercio internacional, es un elemento esencial de las teorías sobre el comercio, tanto la 
neoclásica como aquella más nueva relativa a la estructura del mercado. Después de examinar ambas teorías, y las nociones correspondientes de ventaja comparativa, se compararán ambos argumentos proteccionistas, analizando sus respectivas explicaciones teóricas de las ventajas comparativas y sus recomendaciones en materia de políticas. Se resumirán las críticas hechas al argumento de la industria incipiente y se aplicarán luego al argumento del comercio estratégico para evaluar si el argumento más nuevo resiste someterse a una vieja prueba. En la conclusión se comentará acerca de las repercusiones económicas, políticas e institucionales del argumento del comercio estratégico, y se pondrá en tela de juicio la necesidad de adoptar nuevas teorías sobre el comercio como pautas para las políticas comerciales.

\section{II}

\section{La ventaja comparativa y el comercio internacional}

Según el modelo ricardiano de un solo factor de producción, una economía competitiva produce bienes de acuerdo con dos principios. Los productores intentan elevar al máximo sus ingresos, y el método de producción está determinado por el nivel de progreso técnico del país. Por lo tanto, la cantidad de mano de obra requerida para la producción de un bien está determinada por la técnica de producción. La fuerza laboral de un país se asigna conforme al nivel salarial de los procesos productivos, que en este modelo está determinado por los costos de producción.

La ventaja comparativa se deriva de las diferencias nacionales. En el modelo clásico, la diferencia es la técnica de producción: un país está en condiciones de producir un bien a un costo de oportunidad más bajo en función de la estructura de sus precios relativos internos. Se dice que el país " $A$ " tiene una ventaja comparativa para la produccion del bien "a" si éste se produce a más bajo costo, en relación con el bien "b", que en el país "B". El intercambio comercial se da cuando los países se especializan en la producción del bien para el cual tienen una ventaja comparativa. En la teoría clásica, todos los países obtienen beneficios de la especialización internacional.

\section{La explicación neoclásica}

La teoria del comercio planteada por Heckscher, Ohlin y Samuelson amplía el modelo clásico y simplifica las economías en un modelo con dos factores de producción: mano de obra y capital. Sin embargo, ofrece una explicación diferente de la ventaja comparativa, motor que impulsa el comercio internacional.

En el modelo de dos factores, lo que determina la ventaja comparativa o la estructura de precios relativos es la dotación de cada factor de producción. Un supuesto fundamental es que las técnicas de producción son las mismas para todas las economías. Por consiguiente, el supuesto implícito es que todos los países tienen la capacidad de producir cualquier bien al mismo nivel de productividad marginal de los factores de producción. En otras palabras, la tecnología de producción es de coeficientes fijos y la productividad marginal de la mano de obra y el capital es la misma a través de las fronteras. El comercio internacional es el resultado indirecto de las diferencias de dotación de factores en cada país, no de disparidades en el avance tecnológico. Si se supone un rendimiento a escala que disminuye o es constante, el país se especializará en la producción de bienes que exigen un uso intensivo de los factores que mejor se avengan con su dotación de factores.

Este último elemento de teoría neoclásica es el principal punto de partida de la nueva teoría de comercio estratégico, que hace hincapié en que los costos de producción, la adquisición de insumos intermedios y los conocimientos técnicos afectan a la estructura de determinados mercados estratégicos que ofrecen oportunidades para una mayor acumulación de capital.

\section{La estructura del mercado, la historia y la suerte ${ }^{1}$}

La teoría del comercio estratégico explica por qué la 1 Esta sección se basa en Krugman (1987a, 1987b, 1988, 1990a,
$1990 \mathrm{~b}$ y 1990c). 
producción tiende a concentrarse en zonas geográficas determinadas. El planteamiento difiere sutilmente de la teoría neoclásica, que trata de explicar dónde se concentra la producción de tipos específicos de bienes.

Al reorientar lo que pretende explicar la teoría del comercio estratégico, Paul Krugman y otros han sostenido que la ventaja comparativa no ló explica todo, y que el aumento de los ingresos puede ser una causa independiente de la especialización y el comercio internacionales. Basándose en modelos de competencia imperfecta que se desarrollaron en el campo de la organización industrial en los años ochenta, los teóricos del comercio estratégico pudieron dar forma a la hipótesis de que las economías de escala pueden ser externas a las empresas, y de que el aumento de los ingresos puede traducirse en una competencia imperfecta. La estructura del mercado, configurada por la existencia o no existencia de economías de escala y de aumento de los ingresos, es uno de los factores determinantes de la dirección y composición dẹl comercio internacional.

Conforme a ese esquema, la historia y la suerte cumplen un papel decisivo en cuanto a determinar la orientación del comercio. Ya que se da por supuesto que la acumulación de capital es indispensable para concebir ciertas industrias, el efecto de las economías de escala se ha manifestado en el rápido crecimiento del comercio intraindustrial internacional a través de todo el período de la posguerra. La ventaja comparativa aún es, según Krugman, el motor que impulsa el comercio interindustrial.
Pueden surgir industrias oligopolísticas con sistemas de captación de rentas bajo condiciones históricas que continúan indefinidamente en una zona geográfica específica. De acuerdo con Krugman, "Ya sea que se prefiera atribuir la mayor acumulación inicial de capital en una región al comercio de esclavos o a los principios éticos protestantes, éste es un modelo en el que un comienzo modesto puede tener grandes consecuencias".

Quizás la explicación del comercio internacional basada en la estructura del mercado describa los mercados nacionales e internacionales en forma más realista. Su énfasis en la competencia imperfecta tiene la virtud de incorporar factores que afectan a la base productiva de un país, pero además "no ofrece ninguna garantía de que los beneficios potenciales del comercio vayan necesariamente a hacerse realidad". En consecuencia, proporciona una justificación clara para la formulación de políticas comerciales activas, las que, de acuerdo con la lógica de la teoría, deben ser guiadas de modo de extraer rentas oligopolísticas a las empresas extranjeras. Para ser adecuados, los mecanismos de política tendrían por ello que estar bien enfocados, con el fin de no distorsionar el comercio impulsado por claras ventajas comparativas. Vale la pena señalar que la industria aeronáutica, la de semiconductores y otras de alta tecnología se hallan entre los candidatos favoritos para la protección estratégica.

No obstante, este planteamiento no es el primero que considera factores que afectan a la base productiva.

\section{III}

\section{El argumento de la industria incipiente}

$\mathrm{El}$ argumento de la industria incipiente que se esgrime tradicionalmente en favor del proteccionismo incorpora además como factor los costos de producción. Comprar tecnología y conocimientos técnicos es costoso. Al comienzo, los costos marginales pueden ser superiores a la productividad marginal de la mano de obra y el capital en ciertas actividades productivas, especialmente aquellas que requieren técnicas avanzadas tanto de fabricación como de gestión administrativa.

El supuesto básico es que algunas industrias al comienzo no son competitivas internacionalmente, pero que en el largo plazo, y después de una protección temporal, tienen una ventaja comparativa (Milner, 1988). En el plano teórico, la pregunta más frecuente es por qué ciertas industrias no pueden florecer si no se las protege de la competencia extranjera. Una respuesta común es que las empresas nacientes pueden aprender por la práctica, y que a la larga adquieren competitividad internacional.

\section{La tecnología, los conocimientos técnicos y el aprendizaje por la práctica}

El argumento de la industria incipiente es un planteamiento explícitamente dinámico en favor de la 
protección comercial temporal. En tanto que da por sentado que las empresas pueden superar el período incipiente si se las protege temporalmente, supone también que los costos iniciales de protección serán contrapesados por los beneficios a largo plazo. La justificación de la protección se desvanece con el tiempo.

El aprendizaje por la práctica puede dar cabida a que las empresas se desarrollen si se las ayuda a sufragar los costos iniciales de importación de tecnología, capacitación de la fuerza laboral y mejoramiento de la gestión administrativa. Por ello se sostiene a menudo que la protección de las industrias incipientes debe alcanzar una forma "optima". El objetivo de la protección óptima es crear industrias con márgenes más elevados de utilidades y de ese modo ampliar la frontera de posibilidades de producción de la economía, con el objeto de incrementar a la larga el bienestar de la sociedad. (Johnson, 1966).

Los mecanismos de política comercial, como los aranceles y las cuotas, pueden no ser adecuados para lograr dichos objetivos.

\section{Los mecanismos de polítlca comercial y la superación de las distorsiones del mercado}

El debate en torno a los mecanismos de política comercial lleva al problema de determinar por qué la industria no puede desarrollarse sin intervención. Al haber altos costos fijos iniciales, cuando el ingreso marginal es más bajo que el costo marginal, las opciones de política comercial pueden orientarse hacia el mejoramiento directo de esa carga inicial. Las subvenciones a la producción podrían cumplir la tarea sin rebajar el bienestar de los consumidores. Sin embargo, se ha sostenido también que los aranceles, o en lo que a eso respecta, las cuotas, ${ }^{2}$ aun si se los mantiene indefinidamente, pueden a la larga transformar industrias incipientes en productores competitivos en el mercado nacional e internacional mediante el aprendizaje por la práctica (Johnson, 1966, p. 30).

No obstante, la política comercial en este caso tiene como fin superar lo que puede considerarse

\footnotetext{
2 Jagdish Bhagwati ha explicado que en el caso de modelos que suponen i) una oferta extranjera competitiva, ii) una competencia perfecta en la producción interna y iii) una cuota que se asigna con el fin de asegurar la competencia perfecta entre los tenedores de la cuota, tanto los aranceles como las cuotas tienen el mismo efecto en la estructura de precios relativos de las importaciones y los de los bienes producidos en el país (Bhagwati, 1966, p. 54).
}

una distorsión del mercado. Si no hubiera esa distorsión, y las industrias incipientes fueran percibidas por los mercados financieros como "niños capaces de crecer", los intermediarios financieros deberían proporcionar el crédito necesario para el desarrollo de las industrias. Las instituciones financieras podrían percibir una utilidad futura en términos de valor actualizado si se ofreciera crédito a largo plazo, o por lo menos con un plazo suficiente para que las empresas pudiesen hacer pagos por servicios después de haber realizado el aprendizaje por la práctica.

Por consiguiente, el problema se convierte en la búsqueda de una solución a las distorsiones en el mercado financiero, no en el mercado de bienes. $\mathrm{Si}$, de acuerdo con lo expresado por Bhagwati, "la absurda suposición de que el aprendizaje sigue automáticamente a la práctica" fuese correcta, la distorsión que necesita corregirse es la de que los mercados financieros captan "plenamente los beneficios de ese proceso de aprendizaje para las empresas de las industrias incipientes protegidas o promovidas" (Bhagwati, 1988, pp. 97 y 96, respectivamente).

De hecho, en una jerarquía de opciones, el argumento de la industria incipiente colocaría las intervenciones comerciales directas en un lugar muy bajo (Milner, 1988, p. 67) Además, las subvenciones temporales serían preferibles a los aranceles o cuotas porque no habría necesidad de modificar las características del consumo. Cuando se recurre a subvenciones, el Estado se convierte en el árbitro; la responsabilidad de determinar quiénes son los ganadores y quiénes los perdedores recae en el presupuesto fiscal. Que se haya usado el argumento de la industria incipiente como justificación de una aplicación indefinida de aranceles, e incluso del aislamiento total de las economías en desarrollo, es un "hecho político, no es siempre una necesidad económica" (Johnson, 1966, p. 30)

Si bien estaba orientada a abordar el deterioro a largo plazo de la relación de precios del intercambio para los exportadores de bienes primarios y las fuentes estructurales de la inflación, la estrategia de industrialización mediante la sustitución de las importaciones incorporó el argumento de la industria incipiente en su defensa del proteccionismo. En consecuencia, muchas de las críticas a esta apología proteccionista están intrínsecas en las críticas a su aplicación a través de la estrategia sustitutiva. 
3. Críticas al argumento de la Industria incipiente y a su aplicaclón por medio de la estrategla de sustituclón de las Importaciones

En 1972, Werner Baer observó que las críticas radicales a Ia industrialización por medio de la sustitución de las importaciones se podrían situar en dos categorías. Los críticos "de mercado" consideran ese método de industrialización "una forma ineficaz de usar los recursos para lograr el desarrollo" (Baer, 1972, p. 101). Los "críticos estructurales" señalan que esa forma de industrialización no logró crear suficientes oportunidades de empleo, "no sólo por los problemas sociales de empleo o subempleo urbano, sino también por sus repercusiones en la distribución de los ingresos" (Baer, 1972, p. 107).

Entre los críticos moderados hubo convergencia respecto a diversos puntos. En primer lugar, fue común la evaluación de que la protección arancelaria se puso en práctica en forma indiscriminada, sin tener en cuenta la promoción de actividades productivas que mostrasen una posible ventaja comparativa. En segundo lugar, se observó que el desarrollo autárquico había fomentado el establecimiento de industrias ineficientes de alto costo en economías que ofrecían mercados pequeños, limitados capitales para inversión y mano de obra no calificada. Ese era especialmente el caso de las industrias que soportaban aitos costos fijos y exigían una producción en gran escala con el fin de rebajar los costos a niveles semejantes a los de los países desarrollados. ${ }^{3}$ En el intento de implantar la competencia interna donde las restricciones habían bloqueado la competencia internacional, los gobiernos terminaron por obstaculizar aún más la formación de economías de escala, y de ese modo prevaleció la ineficiencia.

Otra crítica pone de relieve las tasas excesivamente altas de "protección efectiva". Los bienes de consumo estaban protegidos y se elevaron los precios. Entretanto, las importaciones de bienes intermedios y de capital resultaron de menor costo para las empresas que recibían un tratamiento ventajoso en la aplicación de los controles cambiarios. Esos beneficios eliminaron los incentivos para mejorar la eficiencia al aumentar vertiginosamente las utilidades de las industrias privilegiadas por el clima autárquico.

El común denominador de todas las críticas a la industrialización es la mención al clima autárquico que se creó en las economías de América Latina. La puesta en práctica indiscriminada del proteccionismo produjo empresas ineficientes, en tanto que en los sectores agrícolas, aquellos con las ventajas comparativas más obvias en los mercados internacionales, fueron gravados fuertemente. ${ }^{4}$ El argumento de la industria incipiente sólo puede justificar en términos económicos la subvención de los costos si los mercados financieros son irreparablemente imperfectos. Finalmente, este argumento se centra en las industrias que tienen el potencial de aprender por la práctica, y de superar la etapa incipiente. Sólo un proteccionismo muy selectivo puede ser justificado por el argumento de la industria incipiente.

$\mathrm{El}$ argumento del comercio estratégico es semejante en diversos aspectos. El parecido más obvio está en su nombre. La palabra "estratégico" implica selectividad. Un examen del fundamento de esa validación más reciente del proteccionismo aclarará otras semejanzas que tiene con su antiguo predecesor.

\section{IV}

\section{El argumento del comercio estratégico}

Krugman, al defender el proteccionismo selectivo para la economía de los Estados Unidos, sostiene que no se trata de una cuestión de competitividad global sino

\footnotetext{
${ }^{3}$ Werner Baer da dos buenos ejemplos: la industria automovilística y la siderúrgica (Baer, 1972, p. 101).

${ }_{4}$ Los impuestos al sector agrícola tradicional se aplicaron en tres formas. En primer lugar, la reasignación del crédito y de las inversiones al desarrollo industrial redujo los recursos disponibles para aumentar la eficiencia agrícola. En segundo lugar, la sobrevaloración de los tipos de cambio (para suministrar insumos de fabricación
}

más bien de competencia en aquellos sectores que son de especial valor para la economía (Krugman, 1987b, p.208); el comercio internacional no ocurre

\footnotetext{
importados de bajo costo) perjudicó la competitividad agrícola en los mercados internacionales. En tercer lugar, la combinación de precios altos de las manufacturas producidas en el país y controles de precios de los bienes causó una degradación interna de la relación de precios del interćambio de los sectores agrícolas (Baer, 1972, p. 104).
} 
como sustituto de la migración de los factores de producción, sino que se debe al deseo de aumentar al máximo las utilidades en un mercado con un creciente rendimiento a escala. Krugman procedió entonces a identificar las llamadas industrias estratégicas.

Las industrias estratégicas se pueden definir de dos maneras. Primero, las que pueden lograr un rendimiento a escala cada vez mayor cuando la competencia es imperfecta, siendo las economías de escala internas a la empresa. Segundo, las que pueden alcanzar un alto rendimiento indirectamente, cuando se generan economías de escala externas en un mercado de productos diferenciados (Krugman, 1987b, p.230).

El nuevo argumento en favor del proteccionismo, por lo tanto, no se basa en la estructura del comercio de un país. Krugman no cree en el deterioro a largo plazo de la relación de precios del intercambio para los exportadores de bienes primarios (Krugman, 1988, p. 56). Más bien, la teoría del comercio estratégico se centra en las posibles ventajas de captar un mercado diferenciado específico. Una política comercial activa puede intensificar el desarrollo, según esta lógica, mediante el logro de economías de escala, independientemente de si el mercado es imperfecto o no.

En agudo contraste con el argumento de la industria incipiente, esta validación del proteccionismo es estática. ${ }^{5}$ Justifica el proteccionismo por un período indefinido, o hasta que la participación en el mercado se pierda en manos de competidores extranjeros y desaparezcan las economías de escala.

No obstante, el argumento de la industria estratégica plantea que una política comercial activa es un medio para promover las exportaciones de productos estratégicos. En ese sentido, no propone un planteamiento nuevo; el argumento de la industria incipiente también describe la protección como un medio de aprovechar la posible ventaja comparativa. Las opciones óptimas de política son aquellas que permiten a las empresas alcanzar economías de escala sin distorsionar la estructura de los precios relativos. Las subvenciones directas a la producción, o las inversiones públicas o privadas en infraestructura, por ejemplo, pueden surtir efecto. Estas inversiones no suelen considerarse un mecanismo de política comercial, y ambas opciones insisten en la cuestión del gasto fiscal.

En resumen, quedamos reducidos a una diferencia importante: un modelo estático más nuevo se enfrenta a una justificación dinámica más antigua del proteccionismo. Someter el argumento del comercio estratégico a las críticas formuladas a su antigua contraparte es otra forma de probar borra vieja en odre nuevo.

\section{$\mathrm{V}$ \\ ¿Resiste las viejas críticas el argumento del comercio estratégico?}

Las críticas moderadas al argumento de la industria incipiente giraban en torno al problema del desarrollo autárquico. Es sumamente discutible que los costos de gravar a los sectores tradicionales que son internacionalmente competitivos sean compensados a la larga por un proteccionismo indiscriminado.

La protección estratégica, como se mencionó anteriormente, implica en efecto una selectividad. Sin embargo, lo mismo sucedía en el caso de la inđustria incipiente. La protección estratégica supone una protección indefinida con el fin de extraer renta oligopo-

$\$$ Es digno de destacar que Harry G. Johnson hizo en 1966 esta distinción al comparar el argumento de la industria incipiente con los argumentos del fracaso del mercado (Johnson, 1966, p. 27). lística de los extranjeros. El argumento de la industria incipiente sugiere protección temporal, pero las críticas a la industrialización sustitutiva apuntan a la ineficiente industrialización promovida por un proteccionismo indefinido e indiscriminado. En ese sentido, la más nueva de las dos justificaciones obtiene el punta. je más bajo.

Sin embargo, es también obvio que el argumento de la industria incipiente no justificaba, desde el punto de vista económico, la puesta en práctica de la industrialización sustitutiva en la forma en que ello ocurrió. El peligro del argumento del comercio estratégico es que justifica, desde el punto de vista económico, un componente importante de la estrategia de sustitución de las importaciones: la protección indefinida de industrias específicas. La enseñanza 
que se obtiene de esta comparación no tiene que ver con las virtudes de las teorías comerciales, nuevas o antiguas. Las decisiones con respecto a las estrategias adecuadas para el desarrollo que deben adoptar los países de América Latina no deberían centrarse en la lógica de las justificaciones de las políticas comerciales proteccionistas. Más bien, deberían hacer mayor hincapié en las repercusiones económicas, políticas e institucionales del argumento del comercio estratégico.

\section{VI}

\section{Repercusiones económicas, políticas e}

\section{institucionales}

Dadas las semejanzas entre los argumentos de la industria incipiente y del comercio estratégico, algunas de las repercusiones económicas del proteccionismo temporal y selectivo que ellos prescriben pueden parecer atribuibles a ambos.

Las fuerzas del mercado contribuyeron de manera importante a profundizar la industrialización en América Latina durante la era de la sustitución de las importaciones (Hirschman, 1992, p. 1230). El tamaño del mercado permitió que algunas de las economías de mayor envergadura, mediante vinculaciones regresivas, se desplazaran desde la sustitución de las importaciones de productos primarios hacia la de productos secundarios, y desde la producción đe bienes de consumo hacia la de bienes de capital y otros bienes duraderos. Ese efecto probablemente no ocurriría si se estableciera adecuadamente una política de comercio estratégico, sobre todo porque el mercado interno no es el objetivo de una política estratégica.

Otro elemento de juicio es que la sustitución de las importaciones se inició en respuesta a las crisis internacionales y se hizo más profunda a medida que los mercados internos se liberaban de los vestigios de la depresión de los años treinta. El comercio estratégico, al menos en teoría, tiene objetivos a largo plazo. El hecho de que las políticas estratégicas dependan del mercado mundial les pone peligrosos obstáculos por delante. En tanto que la estrategia se concibe a largo plazo, los mercados mundiales reaccionan ante los ciclos económicos, especialmente aquellos de los mercados exportadores más importantes. Existe el riesgo de que se contraigan compromisos financieros excesivos en los períodos de recesión y se llegue a una situación de insuficiente financiamiento durante los períodos de crecimiento. Los encargados de formular las políticas deben tener presente que las políticas estratégicas deben contar con fondos estatales y financiarse por medio de impuestos. Vale la pena recordar que a menudo se han usado en el pasado políticas comerciales no estratégicas (es decir, no selectivas) para resolver los desequilibrios de la balanza de pagos. El nexo indirecto entre la economía interna y el desempeño de la economía mundial o de los principales mercados de exportación se refuerza cuando se aplican estrategias comerciales de largo plazo. Debe resistirse la tentación a hacer un mal acoplamiento de los mecanismos de política comercial con las metas de balanza de pagos.

La conexión entre las políticas fiscales y el comercio estratégico origina algunas de las repercusiones políticas. Por una parte, si las políticas estratégicas tienen éxito, los aumentos del PIB pueden traducirse en políticas fiscales relajadas, en la misma forma en que la fase exuberante de la industrialización mediante la sustitución de las importaciones se tradujo en políticas públicas que fueron más allá de lo razonable. Si no se mantiene el sentido de selectividad, se exacerba la tendencia de la economía nacional a ir más allá de lo razonable con respecto a la economía mundial. La institucionalización de prácticas de captación de ingresos no es ciertamente la única explicación de por qué las estrategias sustitutivas perdieron su sentido. No obstante, es posible que esas prácticas hayan contribuido mucho a prolongar su existencia.

Las repercusiones institucionales del comercio estratégico son quizás las más importantes. Después de todo, los objetivos son ambiciosos, el enfoque debe ser selectivo y el proceso debe ser flexible. La flexibilidad es especialmente importante durante las fases iniciales de la puesta en práctica de las políticas estratégicas. La teoría es vaga con respecto a qué constituye un sector estratégico, de modo que el proceso institucional debe estar en condiciones de retirar recursos fiscales según el método de tanteos. 
El problema, entonces, es cómo abordar la inercia institucional. ${ }^{6}$ Aparte de las funciones directivas, debe definirse claramente dónde ha de estar el centro de la toma de decisiones en materia de política comercial. Al concentrar tales decisiones en una sola entidad institucional se limitan los canales de influencia burocrática, reduciéndose de esa manera la posibilidad de distraerse de los objetivos comerciales estratégicos. Los gobiernos de Costa Rica y Colombia adoptaron medidas en ese sentido cuando establecieron recientemente ministerios especializados en comercio exterior.

Otro requisito institucional es la apertura de canales de comunicación con sectores estratégicos potenciales. Es decir, se requiere una asociación especial entre el sector empresarial y el gobierno basada en un sistema de consultas. Los canales deben institucionalizarse, dando carácter público a las consultas y a la recopilación de información, con el fin de impedir que intereses específicos los dominen. Debe recordarse constantemente a quienes formulan las políticas que las decisiones del pasado pueden no haber sido ideales, especialmente en las fases iniciales de aplicación de las políticas estratégicas. El sistema de consultas públicas está muy avanzado en los Estados Unidos donde, dicho sea de paso, la Oficina del Representante Comercial ha establecido, por prerrogativa legislativa, un sistema permanente de consultas. Al igual que los ministerios de comercio exterior de Costa Rica y Colombia, esa Oficina es más que nada un organismo de negociación internacional. ${ }^{7}$ En los Estados Unidos las subvenciones y otras formas de protección son supervisadas y lievadas a la práctica por el Departamento de Comercio y el Departamento del Tesoro. Además, la Comisión de Comercio Internacional de ese país realiza investigaciones en materia de comercio para el Congreso y la rama ejecutiva, según se lo soliciten, y participa en el proceso de determinar si las industrias de los Estados Unidos han sido perjudi-

6 A. O. Hirschman escribió que las instituciones especiales designadas para suministrar capital y orientación empresarial adquirieron importancia en la mayor parte de América Latina después de que ya estaba en marcha el proceso de industrialización mediante la sustitución de las importaciones (Hirschman, 1971, p. 95).

7 No concentrar en una institución la facultad de negociación comercial puede también originar problemas. Por ejemplo, en un proceso de liberalizacion comercial regional, puede que sea debatible la secuencia de las negociaciones. Es posible que surjan diferencias entre las opiniones de los ministros de hacienda, economía y relaciones exteriores. Esos conflictos pueden producir atascamientos de las políticas. Sin embargo, ese es un tema diferente que rebasa los límites de este artículo. cadas en forma apreciable por prácticas comerciales desleales de otros países.

En el presente artículo se recomienda, a los países grandes y más industrializados de América Latina, la creación de un organismo de política comercial más poderoso y de mayor alcance que la Oficina del Representante Comercial de los Estados Unidos. Se justifica además un grado más alto de concentración de las facultades ejecutivas con respecto a problemas comerciales en países cuya relación comercio-PIB sea alta. ${ }^{8}$

No obstante, se debe hacer mucho hincapié en el hecho de que ciertos sectores no son estratégicos. Por ejemplo, es difícil sostener que las pequeñas economías agrícolas ofrecen opciones estratégicas. A esos países les conviene más bien no arriesgar la estabilidad de sus políticas fiscales. Su economía debe especializarse de conformidad con conceptos más tradicionales de ventaja comparativa. No resulta sorprendente que países con mercados internos pequeños fueran los que tuvieron menos éxito en su período de industrialización sustitutiva. En el caso de los países en desarrollo más grandes e industrializados el centro que toma las decisiones comerciales estratégicas no debe incluir ciertos sectores. En otras palabras, los departamentos de agricultura y comercio interno no deben desaparecer absorbidos por una institución poderosa de comercio exterior. Tampoco se debe gravar a los sectores tradicionales mientras se subvenciona a los estratégicos. Al final, los sectores más claramente competitivos son los que producirán la acumulación de capital para financiar las políticas estratégicas. Los consumidores pagan las políticas comerciales estratégicas a través de la tributación.

Para concluir, las políticas de comercio estratégico requieren nuevas formas de organización del gobierno. En teoría, la justificación de esas políticas tiene semejanzas con la del proteccionismo en el pasado. Sin un pensamiento político e institucional nuevo, la teoría del comercio estratégico sigue siendo borra vieja en odre nuevo.

(Traducido del inglés)

\footnotetext{
${ }^{8}$ En los Estados Unidos esa relación es inferior al $15 \%$.
} 


\section{Bibliografia}

Baer, Werner (1972): Import substitution and industrialization in Latin America: experiences and interpretations, Latin American Research Review, vol. VII, No 1, Austin, Texas, The University of Texas Printing Division, primavera.

Bhagwati, Jagdish (1966): On the equivalence of tariffs and quotas, Trade, Growth, and the Balance of Payments. Essays in $\mathrm{Ho}$ nor of Cotffied Haberler, Chicago, Illinois, Rand McNally \& Co.

(1988): Protectionism, Cambridge, Mass, MIT Press.

Bianchi, Andrés, Robert Devlin y Joseph Ramos (1987): El proceso de ajuste en la América Latina, 1981-1986, El trimestre económico, vol. LIV (4), $\mathrm{N}^{0} 216$, México, D.F., Fondo de Cultura Económica, S.A., de C.V., octubre-diciembre.

De la Torre, Rodolfo (1990): En busca de una perspectiva económica general: conversación con Jagdish Bhagwati, $E l$ trimestre económico, vol. LVII (4), $\mathrm{N}^{\circ} 228$, México, D.F. Fondo de Cultura Económica, S.A. de C.V., octubre-diciembre.

González, Norberto (1988): Una política económica para el desarrollo, Revista de la CEPAL, $\mathrm{N}^{\circ} 34$ (LC/G. 1521-P), Santiago de Chile, Comisión Económica para América Latina y e] Caribe (CEPAL), abril.

Hirschman, A.O. (1971): The political economy of import-substitution industrialization in Latin America, A Bias for Hope, Londres, Yale University Press.

(1992): Industrialization and its manifold discontents: West, East and South, World Development, vol. 20, No 9, Oxford, Reino Unido, Pergamon Press Ltd., septiembre.

Johnson, Harry G. (1966): Optimal trade intervention in the pre- sence of domestic distortions, Trade, Growth, and the Balance of Payments. Essays in Honor of Gotfried Haberler, Chicago, Illinois, Rand McNally \& Co.

Krugman, Paul R. (1987a): Is free trade passe?, The Journal of Economic Perspectives, vol, 1, $\mathrm{N}^{*} 2$, Nashville, Tennessee, The American Economic Association, otonto.

(1987b): Strategic sectors and international competition, Robert M. Stern (ed.), U.S. Trade Policies in Changing World Economy, Cambridge, Mass., MIT Press.

(1988): La nueva teoría del comercio internacional y los parses menos desarrollados, El trimestre econónico, vol. LV (I). N $N^{\circ} 217$, México, D.F., Fondo de Cultura Económica, S. A. de C.V., enero-marzo.

(1990a): Import protection as export promotion: international competition in the presence of oligopoly and economies of scale, Paul R. Krugman, Rethinking Intenational Trade, Cambridge, Mass., MIT Press.

(1990b): Trade, accumulation, and uneven development, Paul R. Krugman, Rethinking International Trade, Cambridge, Mass., MIT Press.

(1990c): Increasing returns and the theory of international trade, Rethinking Intemational Trade, Cambridge, Mass, MIT Press.

Milner, Chris (1988): Trade strategies and economic development, David Greenaway (ed.), Economic Development and International Trade, Nueva York, St. Martin's Press.

Riedel, James (1988): Trade as an engine of growth: theory and evidence, David Greenaway (ed.), Economic Development and International Trade, Nueva York, St. Martin's Press. 